DOI: https://doi.org/10.24867/08FA12Obradovic

\title{
INTERAKTIVNA PREZENTACIJA JEDNOPORODIČNOG STAMBENOG OBJEKTA KORIŠĆENJEM VIRTUELNE REALNOSTI
}

\author{
INTERACTIVE PRESENTATION OF A HOUSE BY VIRTUAL REALITY
}

\author{
Miloš Obradović, Fakultet tehničkih nauka, Novi Sad
}

\section{Oblast - ARHITEKTURA}

Kratak sadržaj - U radu je prikazana interaktivna prezentacija jednoporodičnog stambenog objekta pomoću virtuelne realnosti. Predstavljeni su $i$ analizirani svi postupci koji od projektovanja objekta vode do postupka primene interaktivne virtuelne realnosti $u$ arhitekturi.

Ključne reči: vizuelizacija, virtuelna realnost

\begin{abstract}
The aim of this paper is the presentation of house using virtual reality. The paper presents and analyzes all the procedures that lead from the design of the house to the process of applying interactive virtual reality in architecture.
\end{abstract}

Key words: visualization, virtual reality

\section{UVOD}

Tehnologija virtuelne realnosti (Virtual Reality - VR) je termin koji se koristi za opisivanje trodimenzionalnog okruženja koje generiše računar, a koje osoba može da istraži i sa kojim može da komunicira [1].

Pojava virtuelne realnosti u arhitekturi jedna je od velikih novina u poslednjih nekoliko godina. Za mnoge industrije koje se oslanjaju na dizajn, najveći izazov je često kako uveriti klijenta da će gotov projekat izgledati barem isto, ili čak i bolje, nego što izgleda $3 D$ prezentacija. Sada $V R$ tehnologija ima mnogo potencijala za primenu $u$ arhitekturi [2].

Uz razvoj i napredak arhitekture, dolazi do razvoja tehnologije, a $3 D$ prezentacija postaje glavna alatka arhitektonske reprezentacije. Visok stepen realističnosti $3 D$ prikaza je omogućen uz razvoj softvera, a pored istog, vizualizacija je morala da bude unapređena na određeni način. Jedan od načina uz pomoć kojih se vizualizacija i doživljaj prostora znatno bolje i brže razvijaju jeste virtuelna realnost.

U svetu arhitekture, vizualizacija se javlja kao jedna od najbitnijih tema, a svaki projekat se može prezentovati na mnogo načina - korišćenjem ortogonalnih crteža, $3 D$ prikaza, fotorealističnih rendera, animacije, proširene realnosti (Augmented Reality), virtuelne realnosti i slično. $\mathrm{U}$ ovom radu akcenat će biti stavljen na virtuelnu realnost (Virtual Reality - VR) kao budućnost arhitekture koja je sve više prisutna, kao sastavni deo bilo kog arhitektonskog projekta.

\section{NAPOMENA:}

Ovaj rad proistekao je iz master rada čiji mentor je bila dr Vesna Stojaković.
$\mathrm{Uz}$ pomoć $V R$-a korisnik biva izmešten u drugačiju dimenziju u kojoj je interaktivan sa digitalnim objektima, koristeći sve što se nalazi u njegovom virtuelnom okruženju. Na taj način, korisnik menja način gledanja na određeni događaj, mesto i prostor, tako što i sam učestvuje $u$ istom.

\section{NAČINI PREZENTACIJA ARHITEKTONSKIH OBJEKATA}

Arhitektonski projekat moguće je prezentovati na mnogo načina. Isti se najčešće prezentuju korišćenjem ortogonalnih crteža, $3 D$ prikaza, i fotorealističnih rendera, a neretko se kao alat prezentacije koriste animacije, proširena realnost i virtuelna realnost. Da bi jedan arhitektonski projekat bio kompletiran, potrebno je od ideje doći do realizacije.

\section{VIRTUELNA REALNOST KAO NAČIN PREZENTACIJE OBJEKTA}

Definicija virtuelne realnosti može da bude kompjuterski generisano maštanje, a kako se razvija kompjuterska tehnologija, granica između digitalnog okruženja i stvarnog okruženja sve je teža za shvatanje. Pogrešno je mišljenje da ideja virtuelne realnosti ima veze samo sa video-igrama. Ova tehnologija je primenjiva u mnogim segmentima života: od arhitekture, sporta, medicine, umetnosti, pa sve do treninga vojnika i radnika [3].

Prezentacija arhitektonskog objekta pomoću virtuelne realnosti jedan je od načina doživljavanja prostora datog objekta. Uz pomoć virtuelne realnosti moguće je "izmestiti se" u drugu dimenziju, sagledati objekat iz potpuno drugačije perspektive, kako nije moguće sagledati ga uz pomoć drugih principa prezentacije. Softver koji se koriste za VR su Unity i Unreal Engine, a u ovom radu je za dobijanje željenih rezultata korišćen Unreal Engine.

\section{ELEMENTI VR APLIKACIJE I OPREMA}

$\mathrm{U}$ zavisnosti od oblasti primene $V R$ tehnologije, određene komponente imaju veći prioritet od drugih. Geometrija se mora izraditi u nezavisnom softveru postupkom $3 D$ modelovanja. Materijali koji se koriste u računarskoj grafici u svrhu prikaza realističnih objekata sadrže elemente prikaza koji se ne odnose samo na boju ili teksturu objekta, već i na fizička svojstva realnih materijala. Osvetljenje scene najčešće se postiže uz pomoć sunčeve svetlosti, za čiju prezentaciju se koriste paralelni sunčevi zraci prema objektima. 
Audio komponente se često zanemaruju, ali mogu značajno uticati na impresivnost iskustva $\mathrm{u} V R$ aplikaciji. Interakcija sa objektima i elementima virtuelnog okruženja podrazumeva određeno programiranje i predviđanje situacionih scenarija prilikom korišćenja različitih objekata. Korisnički interfejs (eng. User interface - UI) predstavlja niz različitih prikaza ili delova prikaza na kojima se nalaze informacije ili opcije prilikom korišćenja $V R$ aplikacije. [4]

Za primenu $V R$-a je osim opreme potreban i računar određenih specifikacija, kako bi doživljaj bio kompletan. Preporučuje se upotreba desktop računara, jer laptop računari ne garantuju podršku $V R$ uređaja. Za projekat prikazan u ovom radu je korišćen Oculus Rift.

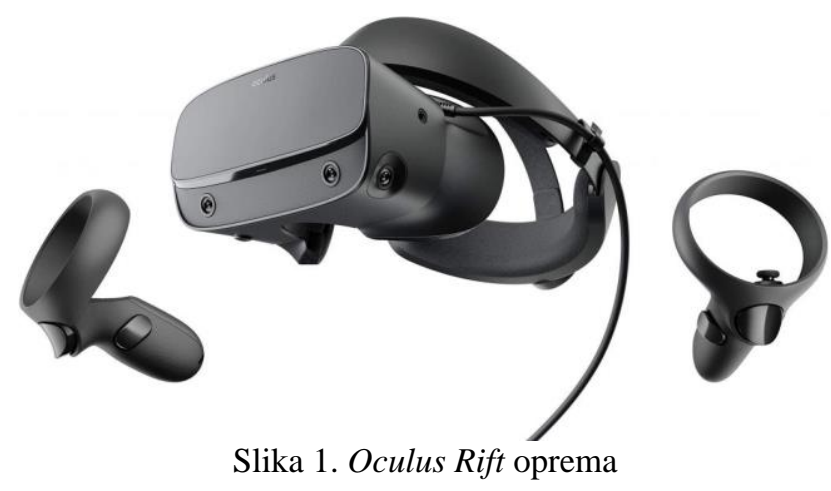

\section{PRIMENA VR TEHNOLOGIJE ZA PROJEKAT JEDNOPORODIČNE KUĆE}

U ovom radu korišćen je $V R$ da bi se došlo do finalnog rešenja problema, definisanog $u$ cilju istraživanja. Kombinacijom primene softvera i VR opreme korisniku je omogućena interakcija sa prostorom.

Određeni segmenti scene treba da budu interaktivni $u$ određenoj meri. Mogućnosti kretanja kroz prostor treba da budu ograničene, kao i mogućnost interakcije sa određenim elementima u sceni. Mora da postoji razlika između onoga kako korisnik može interaktivno da reaguje na scenu u softveru. Jedan način je da učestvuje u sceni koristeći računar, kada se interakcija obavlja putem firstperson template-a, a drugi način je da se interakcija odvija putem VR template-a, kada je korisniku, pored računara, potrebna i odgovarajuća oprema kako bi interakcija mogla da bude kompletna.

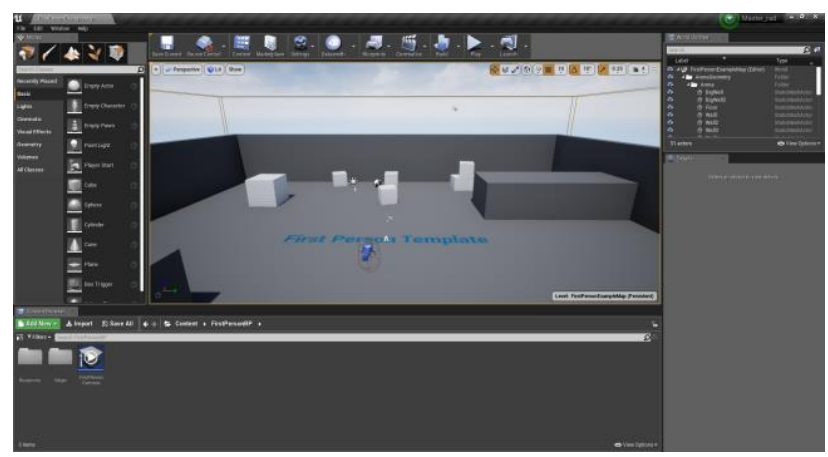

Slika 2. Interface first-person template-a

\section{PRIMENA $V R$-A U ARHITEKTONSKOJ VIZUALIZACIJI}

Tek kada je model sređen, kada su materijali adekvatno postavljeni na model i kada postoje odgovarajuća svetla, moguće je preći na primenu $V R$-a u arhitektonskoj vizualizaciji. Potrebno je odrediti koje će opcije korisnik moći da koristi prilikom virtuelne šetnje kroz scenu, a u okviru rada na jednoporodičnoj kući moguće je vršiti teleportaciju kroz prostor, hvatanje pojedinih modela, podizanje i premeštanje ili bacanje istih, kao i menjanje modela unutar scene uz pomoć kontrolera.

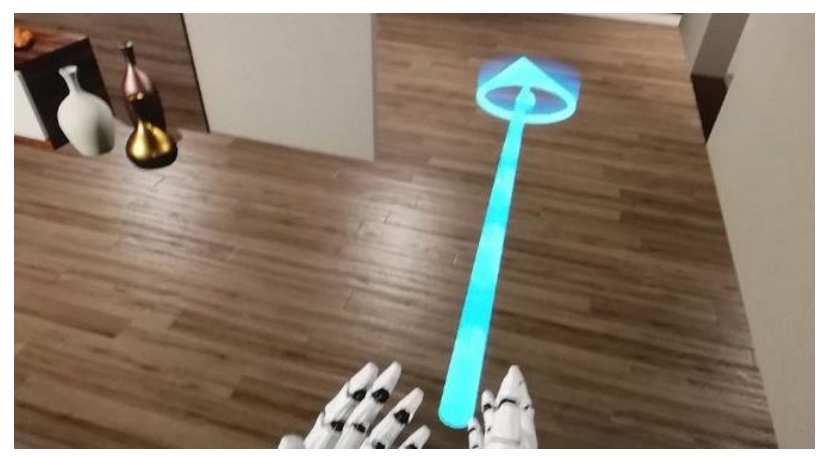

Slika 3. Teleport kroz scenu

Da bi korisnik mogao da se kreće kroz scenu, potrebno je da koristi kontrolere. U unapred definisanom opsegu kretanja, klikom na određeno dugme kontrolera moći će da se teleportuje na željenu lokaciju. Problem koji se najčešće javlja u ovakvim slučajevima jeste nemogućnost teleportovanja.

Kako bi bio kreiran efekat menjanja objekta ili materijala klikom na dugme kontrolera, potrebno je koristiti Blueprint-ove. Na primer, ukoliko bi korisnik želeo klikom na dugme kontrolera da promeni model $\mathrm{u}$ potpunosti, morao bi da mu se približi do odgovarajuće blizine (unapred utvrđene), kako bi model mogao da reaguje na kontrolere, te da bude zamenjen.

Ovakav način biranja između dva modela može da bude interesantan korisnicima, ali kao i kod podizanja pojedinih elemenata, nedostatak je taj što je za svaki pojedinačni segment koji treba da bude zamenjen, potrebno kreirati odvojeni Blueprint. Iz tog razloga, u radu jednoporodične kuće moguće je zameniti sofu u dnevnom boravku klikom na određeno dugme kontrolera.

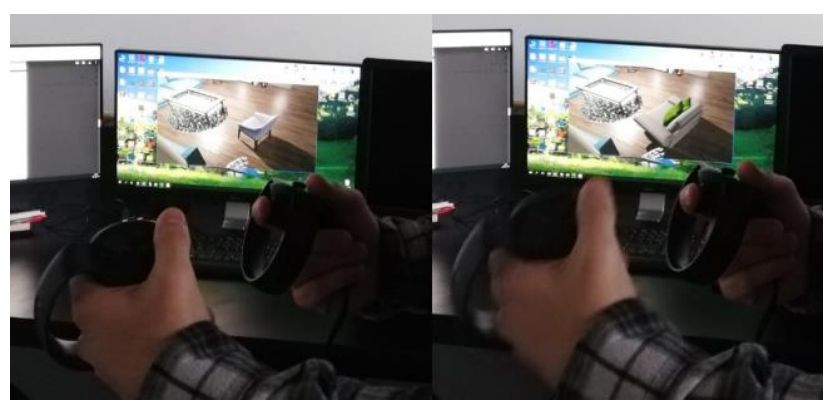

Slika 4. Interaktivno menjanje modela

Motion Controller Template sadrži box koji se može koristiti interaktivno. Reč je o asset-u koji je programiran tako da se uz pomoć virtuelnih ruku isti može pomeriti, podići i baciti, a sve to u toku virtuelne šetnje kroz scenu. Ove mogućnosti su obezbeđene Blueprint-om, koji se može primeniti na asset-e po želji. Ono što je bitno jeste da kolizija za date objekte bude što detaljnije naneta, tako da, primera radi, na određeni high-poly model mora da se 
iskoristi kompleksna kolizija, jer postoji mogućnost da se postavljanjem obične kolizije na kompleksniji asset neće dobiti isti efekat, kao kada se na kompleksniji objekat stavi kompleksna kolizija.

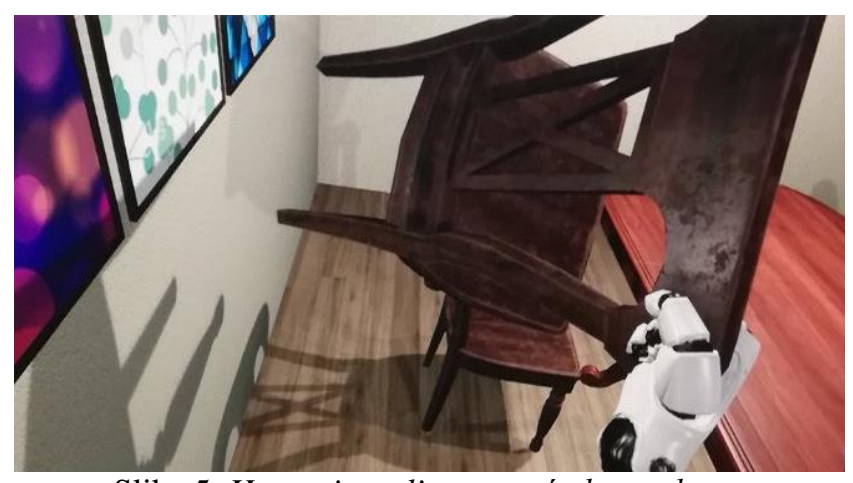

Slika 5. Hvatanje stolice pomoću kontrolera

\section{ZAKLJUČAK}

Prilikom pripreme rada najpre je bilo potrebno projektovati, pa potom i u velikoj meri modelovati prizemni jednoporodični stambeni objekat. Za pripremu modela korišćeni su softveri ArchiCAD i $3 d s$ Max, kao i asset-i preuzeti sa interneta. Sledeći korak bio je importovanje modela u Unreal Engine softver, a nakon rada u istom projekat je pripreman za izvedbu u $V R$-u.

Nivo detaljnosti finalnog projekta zavisi od uloženog vremena, materijalizacije, kao i osvetljenja, te detaljnost obrade modela pred pripremu za $V R$ nije uvek ista. $\mathrm{U}$ zavisnosti od toga šta je primarni cilj virtuelne realnosti zavisi i nivo detaljnosti objekta, kao i njegove okoline. Okolina objekta sadrži zadovoljavajući nivo detaljnosti, te ni u jednom segmentu ne ostavlja korisnika u nezavršenom prostoru, dok je prostor u koji nije moguće pristupiti adekvatno označen.

Kako bi virtuelna šetnja bila kreirana, potrebno je proći kroz tri koraka, gde je prvi korak predstavljen kreiranjem ideje, drugi kreiranjem $3 D$ modela, a treći implementacijom i povezivanjem sa virtuelnim prostorom. $\mathrm{Na}$ osnovu istraživanja $V R$-a u arhitekturi, jedna od prednosti je osećaj prisustva u virtuelnom prostoru u kom se korisnik fizički ne nalazi, interaktivan odnos između korisnika i elemenata u virtuelnom prostoru, postojanje određenog stepena fotorealističnosti, velik broj gotovih materijala, kao i interaktivne senke, neke su od prednosti $V R$-a. Kako bi mogao da pristupi virtuelnoj šetnji, korisnik treba da poseduje opremu, čija cena nije niska, dok postoji i mogućnost pojave mučnine prilikom nošenja opreme. Uobičajeno je usporenje softvera kod većih scena, kao i neadekvatan način apliciranja materijala na elemente $u$ sceni.

Kroz niz istraživanja na temu virtuelne realnosti dolazi se do zaključka da efektivnost $V R$-a zavisi od stepena fotorealizma projekta, kao i od želje autora da akcenat stavi na pojedine segmente projekta. Zaključak rada jeste da primena $V R$-a u Unreal Engine-u ima više prednosti nego nedostataka, a jedan od najvećih nedostataka je da je ova tema $\mathrm{i}$ dalje nedovoljno istražena i primenjena kod nas. Prednosti su, pored dobrih vizuelnih efekata, mogućnost komunikacije korisnika sa virtuelnim prostorom, pristupačnost softveru, širok spektar mogućnosti vezan za korišćenje istog, kao i znatno bolji vizuelni efekat u odnosu na Unity softver, za relativno slično vreme upotrebe softvera.

Rezultat koji je dobijen se razlikuje od uobičajnih načina prezentacije, jer korisnik ima mogućnost interakcije sa prostorom. Takođe, $V R$ u arhitekturi pokazuje pozitivan efekat na korisnike, a njena delotvornost će sigurno uticati na poboljšanje i proširenje mogućnosti arhitektonske vizualizacije u budućnosti.

\section{LITERATURA}

[1] Donovan Alexander; How VR Technology Is Changing the Way Architects Design Your Home https://interestingengineering.com/how-vr-technology-ischanging-the-way-architects-design-your-home

[2] MD STUDIO LTD; Virtual Reality Uses in Architecture and Design https://medium.com/studiotmd/virtual-reality-uses-inarchitecture-and-design-c5d54b7cle89

[3] Edu; Šta je to virtuelna realnost? http://www.edutelevision.com/nauka/tehnologija/sta-jeto-virtuelna-realnost

[4] Predrag Šiđanin, Marko Lazić; Virtuelna i proširena realnost, koncepti, tehnike, primene; 2018.

\section{IZVORI FOTOGRAFIJA}

1. Slika 1 - https://vrheadsetauthority.com/beststandalone-vr-headsets-for-2019/;

pristupljeno 14.10.2019.

2. Slika 2 - screenshot, autorska fotografija

3. Slika 3 - autorska fotografija

4. Slika 4 - autorska fotografija

5. Slika 5 - autorska fotografija

\section{KRATKA BIOGRAFIJA}

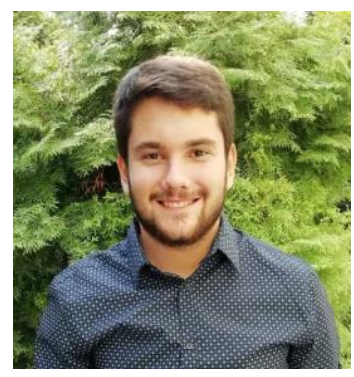

Miloš Obradović rođen je 5. decembra 1995. godine u Novom Sadu, gde trenutno živi. Završio je Osnovnu školu "Ivo Lola Ribar", potom je upisao Gimnaziju "Jovan Jovanović Zmaj" 2010. godine i završio je 2014. godine. Iste godine je upisao studijski program Arhitektura i urbanizam na Fakultetu tehničkih nauka $\mathrm{u}$ Novom Sadu, koji je završio 6 . septembra 2018. godine. Iste godine je upisao master studije na smeru Digitalne tehnike, dizajn i produkcija u arhitekturi i urbanizmu na Fakultetu tehničkih nauka u Novom Sadu. 